\title{
La Biblioteca de la Universidad de Zaragoza en la web 2.0
}

Luis Blanco, Alberto Galán, Consuelo Marco, Miguel Martín, Adriana Oliva, Lidia Plumed, José Manuel Ubé Biblioteca de la U. Z. - Subcomisión Web 2.0 - Zaragoza, España

\section{OBJETIVOS}

I. Implantación y desarrollo de las herramientas de la web social en la BUZ para dar más visibilidad a la Biblioteca, a sus servicios, actividades y recursos en la sociedad.

2. Establecer un canal directo de comunicación con el usuario donde podremos responder a posibles dudas que le surjan de una manera inmediata. Nos permitirá, también, crear una nueva vía para satisfacer las necesidades de información de nuestros usuarios y de los que aún no lo son.

3. Crear un modelo que fomente la lectura y la participación, con la colaboración del personal de la BUZ y del usuario en la creación de contenidos.

\section{METODOLOGÍA}

I) Un Grupo de trabajo elabora un análisis previo de la situación y estudio de las Herramientas sociales para su posible implantación en la BUZ (2010).

2) Creación de una Subcomisión dentro de la BUZ para la puesta en marcha de dichas herramientas Web 2.0 (201I) y para el desarrollo de sus objetivos. Está compuesta por 7 personas dedicadas a la web social: Dos personas para la generación de contenidos y el mantenimiento de blog "Tirabuzón" de la BUZ, con una media de 2 entradas semanales; 4 personas se ocupan diariamente (en turnos de mañana y tarde) de las entradas y comentarios del Facebook y Twitter de la BUZ. El otro componente de la Subcomisión se encarga del soporte técnico e informático de todas las herramientas.

\section{3) Herramientas sociales utilizadas:}

Blog Tirabuzón:

http://blog.biblioteca.unizar.es/

Facebook:

http://www.facebook.com/Biblioteca.Universidad.de.Zaragoza

Twitter:

http://twitter.com/bibliouz

4) Creación del Boletín semanal iBuz, recopilatorio de las noticias publicadas en el blog y facebook de la BUZ que se envía a todo el personal de la BUZ vía correo electrónico y que se aloja también en la web de la BUZ: http://biblioteca.unizar.es/iBuz/ibuz.pdf

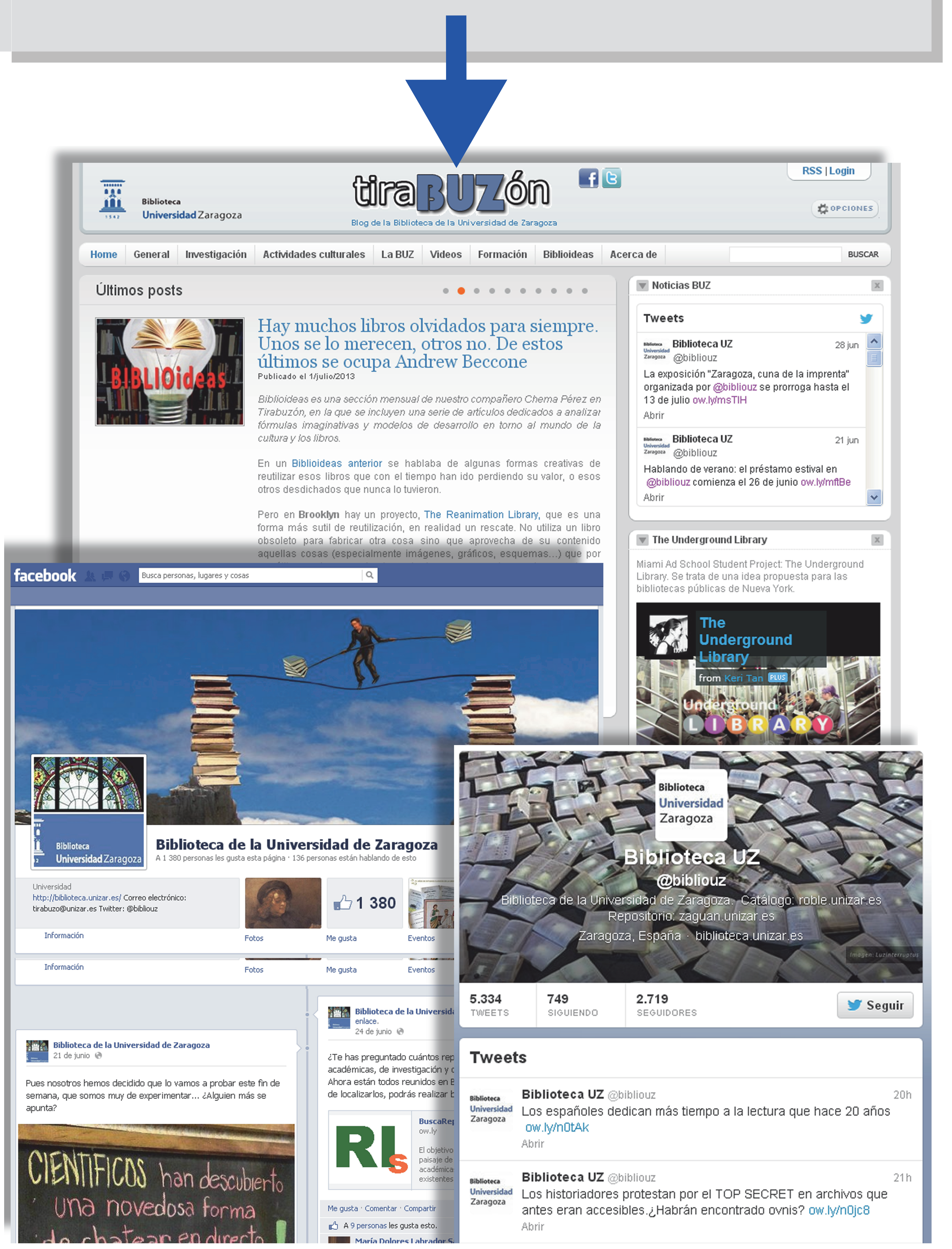

\section{RESULTADOS}

El blog de la BUZ (tirabuzón), su página de Facebook y Twitter comienzan sus publicaciones en marzo de 2011. El incremento de seguidores en Facebook y Twitter ha sido constante (con una media de 100 nuevos seguidores mensuales en Twitter y 45 nuevos fans en Facebook):

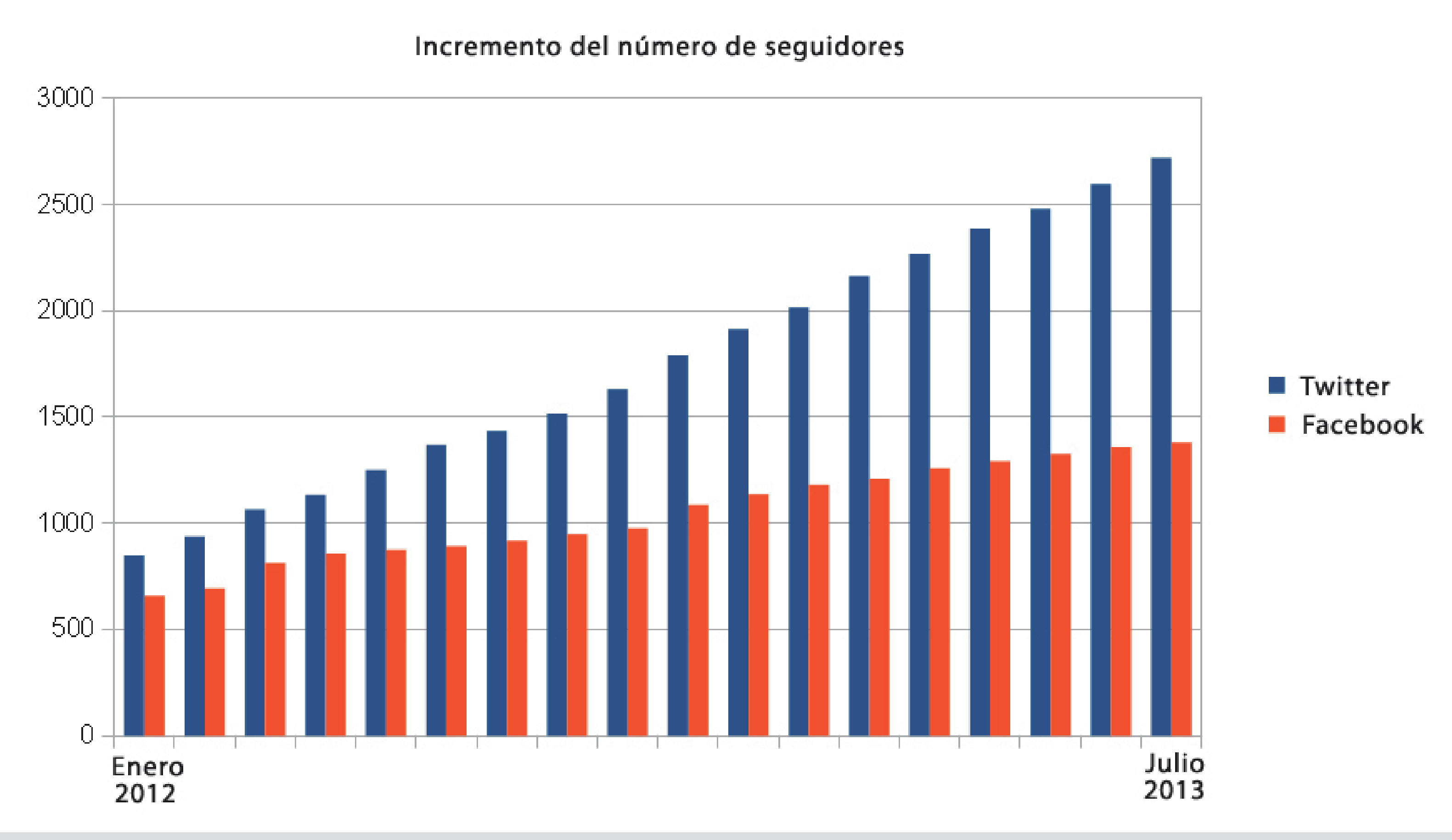

El ritmo de publicación es diferente en cada una de las herramientas. En la siguiente gráfica mostramos el promedio mensual de nuevas entradas en el periodo $2012-2013$.

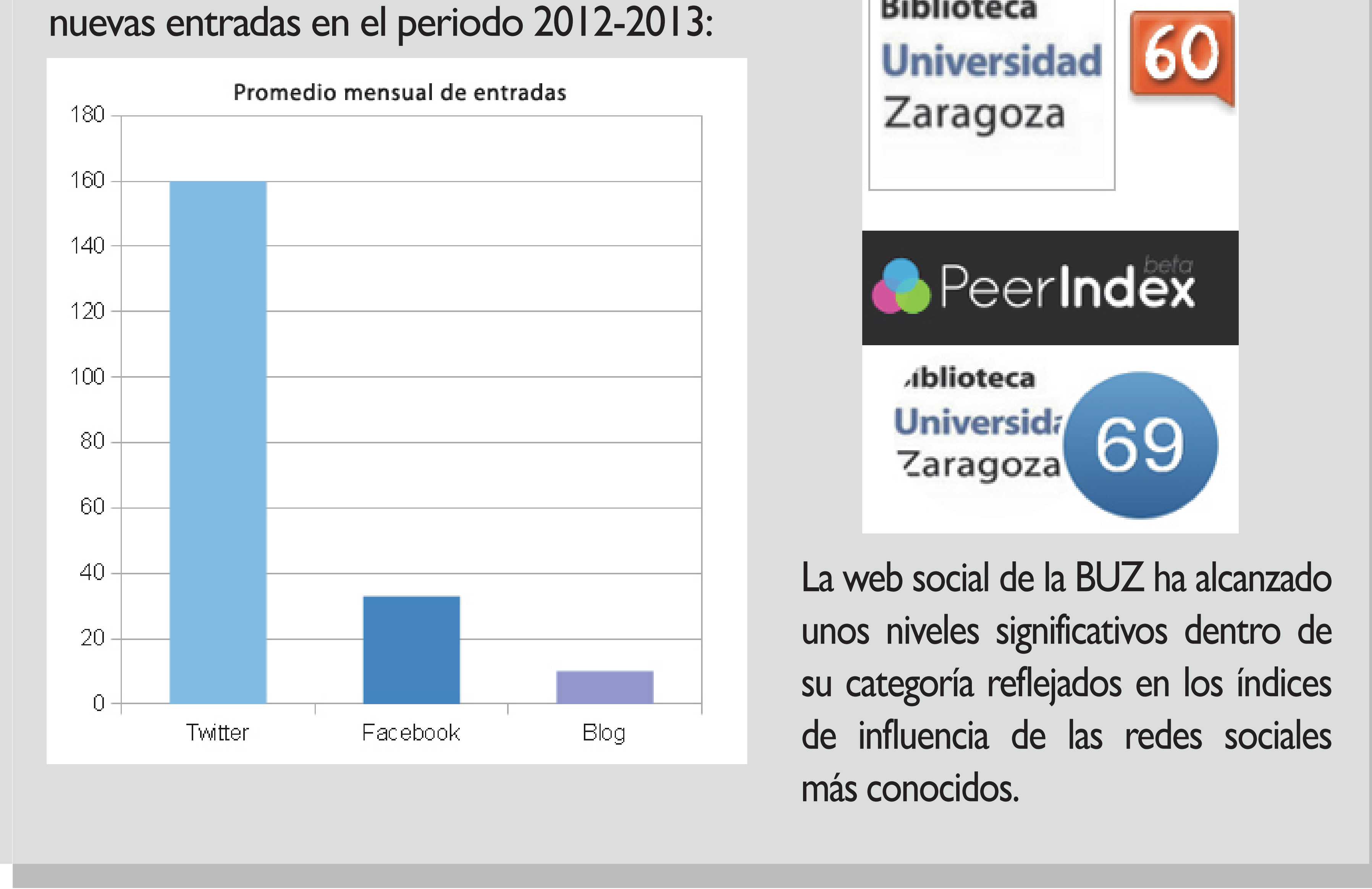

\section{CONCLUSIONES}

Tras dos años de implantación, la web social de la BUZ está consolidada. Gracias a ella, la visibilidad de la BUZ frente a sus usuarios y la sociedad es mucho mayor y abre mâs posibilidades interacción que se suman a las vías de comunicación "tradicionales". Ha crecido el número de seguidores de una manera constante y cada vez es mayor la participación de los usuarios en la misma $\left(n^{\circ}\right.$ de comentarios, retwitts, "me gusta" y "compartir", etc).

La difusión de las herramientas $\mathbf{2 . 0}$ entre todos los potenciales usuarios de la biblioteca es clave para su desarrollo y utilidad práctica. Por ejemplo, se ha insistido especialmente en dar a conocer la web social de la BUZ en los cursos moodle que la biblioteca realiza para alumnos de primero de grado. También se ha incrementado la participación del personal de la biblioteca en los contenidos del blog, algunas veces de forma puntual y otras permanente, como la sección mensual de "Biblioideas" realizada por Chema Pérez Rabinal.

La tipología de las entradas en cada una de las herramientas incluyen temas o actividades propios de la biblioteca junto con noticias generales de la Universidad; además se combinan siempre con información de novedades, servicios, etc del mundo de la información, la investigación científica, etc. de todo el mundo.

La tipología de nuestros usuarios en la web social varía según cada herramienta. En Facebook predomina el usuario joven, en su mayoría estudiante de la universidad. En Twitter, además de numerosos estudiantes, dominan los profesionales de la información y documentación, instituciones científicas o universitarias, otras bibliotecas, etc. 